\title{
Research on the Dynamic Evaluation Mode of Advanced English Teaching
}

\author{
Zhang Youwen (Corresponding author) \\ Zhejiang University of Finance \& Economics Dongfang College, China \\ Email: zyw12398@163.com
}

Received: 09/10/2021

Accepted: 14/01/2022

Published: 01/03/2022

Volume: 3 Issue: 2

How to cite this paper: Youwen, Z. (2022). Research on the Dynamic Evaluation Mode of Advanced English Teaching. Journal of Critical Studies in Language and Literature, 3(2), 16

DOI: https://doi.org/10.46809/jcsll.v3i2.129

This work is licensed under the Creative Commons Attribution International License (CC BY 4.0). http://creativecommons.org/licenses/by/4.0/

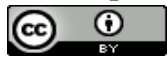

\begin{abstract}
Based on the dynamic evaluation theory, combined with the characteristics of English language teaching and teaching objectives, this paper constructed a dynamic evaluation mode for the "Advanced English" course. The evaluation mode divided Advanced English teaching into four teaching sections: pre-class online self-learning, classroom partner interaction internalization, after-class study notes evaluation and feedback, and subject paper project refinement and improvement; through the establishment of a " curriculum learning portfolio", evaluation runs through the entire teaching process, promotes the organic combination of teaching and evaluation, and realizes the cultivation of students' individual cognitive strategies and the stimulation of their learning potential. The dynamic evaluation mode of Advanced English course plays a positive role in shaping the cognitive structure of students and developing other related course evaluations.
\end{abstract}

Keywords: Teaching and Evaluation, Curriculum Learning Portfolio, Dynamic Assessment

\section{Introduction}

Course evaluation is a key component of teaching, and it is one of the important processes to help achieve teaching goals. With the vigorous development of cognitive psychology, humanistic thinking and modern constructivist thinking have gradually received attention, and the concepts and methods of dynamic evaluation have also been continuously developed and changed. The theoretical basis of dynamic evaluation is derived from the cognitive theory of social development by Vygotsky, the concepts he proposed including social intermediation, internalization, zone of proximal development and scaffolding have a greater impact on the concepts and methods of dynamic evaluation (Vygotsky, 1989). In researching and designing the dynamic evaluation mode, due to the different concepts and focuses, initially several different evaluation modes are derived (Budoff, 1999; Feuerstein, 1990; Campione \& Brown, 1998; Burns, Vye \& Bransford, 1998) . While Lantolf \& Poehner (2004) divided dynamic evaluation into two types: interactionist and interventionist. Dynamic evaluation can observe and evaluate students' progress and change situation across multiple time points, and understand the characteristics and potential of students' dynamic cognitive process and cognitive ability changes (Li Kunchong, 2001). Dynamic evaluation emphasizes a large number of interactions between teachers and students, and enforces the combination of evaluation and teaching. Many scholars also applied dynamic evaluation theory to the practice of language teaching and course evaluation (Ableeva, 2010; Naeini, 2014; Petersen et al., 2016; Li Dandi, 2015; Li Fengqin \& Han Xiaoling, 2017; Chen Dandan, 2021).

"Advanced English" aims at constructing the subject knowledge structure of senior English majors, improving students' comprehensive language ability, and cultivating students' thinking ability. It is a core compulsory course for English majors. The Advanced English course is highly knowledgeable, and the content and themes of the texts and styles are rich and varied. 
course pays more attention to students' ability to use English for original text appreciation, independent thinking and innovation. The emphasis is on assessing the comprehensive language ability of senior students, focusing on reading comprehension, vocabulary and grammar exercises, and strengthening the learning of rhetoric devices.

The shortcomings of the traditional advanced English course assessment system are prominently manifested in the following aspects: (1) Examination is equivalent to evaluation, ignoring the dynamic observation of students' academic growth. (2) The content of the examination is textbookized and formatted, ignoring the assessment of students' ability to use language and seeking differences thinking. (3) The knowledge depth of the assessment is very limited, ignoring the evaluation of students' ability to expand their language knowledge.

In fact, Advanced English is a course rich in connotation. It not only requires reading comprehension, language rhetoric and writing skills, but also cultivates students' knowledge expansion, masterpiece appreciation, logical thinking and independent thinking ability. In addition, it has gone beyond the language knowledge system itself and into other related disciplines. Therefore, we should reorient the course with a development view, and define the course from a knowledgebased course to a course that pays equal attention to knowledge transfer and ability training, making it an innovative platform for cultivating students' learning ability, speculative ability, practical ability, and research ability. The purpose of this research is to explore the diversification of evaluation models in English teaching through the empirical study of the dynamic evaluation mode of Advanced English teaching.

\section{The Design of Experiment}

This experiment was carried out in two parallel classes (24 students/class) for English majors. The project takes dynamic evaluation as the theoretical guidance, the establishment of learning portfolios as the means of implementation, and the ability-orientation as the goal, to carry out innovative and practical action research on the dynamic evaluation mode of "Advanced English". Its significance is mainly reflected in changing the final assessment into process assessment, realizing the shift of the focus of the "development" of education; from knowledge assessment to ability assessment, realizing the goal of holistic education; from "separation of evaluation and teaching" to "combination of evaluation and teaching", realizing the effectiveness of "learning center"; from a single assessment subject to multiple interactions, it promotes the development of social personality in terms of "subjects mutual promotion".

The dynamic evaluation mode of "Advanced English" strives to shift the focus from testing to the learning process, and to achieve an organic combination of summative evaluation and formative evaluation. The content of the research project mainly includes the following five aspects:

1) The Construction of the "Ability-oriented" Dynamic Evaluation Mode

The construction of the dynamic evaluation system of Advanced English course is mainly to divide the teaching process into different stages. At different stages, according to the characteristics of the teaching content and the specific needs of students, through the establishment of a "curriculum learning portfolio", a certain evaluation is involved, so that students are encouraged to master the characteristics of Advanced English learning and basic knowledge framework under the guidance of teachers and the stimulation of teacher-student interdependence. As the intensity of stimulation reaches a certain level, the teacher's guidance is gradually weakened, which eventually encourages students to exert their learning independence and learning potential, and cultivate students' thinking ability and the ability of using comprehensive language knowledge to solve practical problems.

2) Reform of Evaluation Content to Promote the Development of Comprehensive Capabilities

The teaching evaluation content of the "Advanced English" course is determined by its teaching purpose, that is, "to train students' comprehensive English skills, especially reading comprehension, language rhetoric and writing skills, to expand students' knowledge, to deepen students' understanding of society and life, and to cultivate students' ability to analyze and appreciate masterpieces, logical thinking and independent thinking, to consolidate and improve students' English language skills."

Based on this, the "Advanced English" teaching evaluation will evaluate students from two aspects: First, the mastery of basic language knowledge, based on the syllabus and examination outline, to examine students' overall grasp of the knowledge structure system, adopting a quantitative evaluation method. Second, ability to use comprehensive language knowledge, a comprehensive evaluation method (combination of in-class and extra-curricular) is adopted to evaluate students' ability to use language knowledge, utilizing various forms and a qualitative evaluation method

3) Reform of Evaluation Method to Realize Positive Intervention in Development

Teaching evaluation methods are carried out according to the needs of the evaluation content. Since the evaluation content and standards are diverse and comprehensive, the corresponding evaluation methods should also be diversified and scientific. To integrate the teaching practice of "Advanced English" for English majors, we will try the following two teaching evaluation methods.

One is quantitative evaluation. Quantitative evaluation is to assess students' mastery of the basic theoretical knowledge of linguistics in a quantitative way. It is usually a closed-book test. Objective questions account for most of the content, such as vocabulary questions, judgment questions, reading comprehension questions, etc., the subjective questions of solving practical problems and integrating theory with practice are relatively small, mainly testing students' memory and 
comprehension ability of language knowledge. This kind of examination is periodic, such as unit tests, mid-term examinations, etc., or it can be final, such as final exams.

The other is qualitative evaluation. Qualitative evaluation is based on a grading system to evaluate student learning activities or processes, which is generally divided into five grades: excellent, good, medium, pass and fail, with the characteristics of flexibility and openness. It includes four aspects: 1. "Flipped classroom" pre-class assessment. Students change their original learning methods and perform flipped learning based on the short and succinct electronic resources uploaded by the teacher on the network platform in advance. Teachers convert the key points, difficulties and other knowledge points in the textbook into problems before class, and pre-design the "Autonomous Flip Learning Task List" to guide students in learning, online discussions, and self-tests in a task-driven and problem-oriented way. 2."Peer instruction"interactive classroom assessment. According to the grouping principle of "heterogeneity within a group and homogeneity between groups", the cooperation and mutual learning in groups can occur before class, or in the classroom, teachers and students jointly discuss the problems in learning, discussion and research, including answering and solving doubts, applying knowledge, etc., to enable students to achieve their learning goals. 3. "Note-taking" feedback assessment after class. Study notes are a key part of learning this course well. Study notes are not simple class notes, but a comprehensive arrangement and deepening of class studies. In other words, the study notes are based on the students' digestion and absorption of class notes outside of class, re-summarizing the knowledge they have learned, adding their own cognitive components, and deepening the knowledge they have learned more comprehensively and systematically. In this process teachers put forward appropriate supervision and guidance, incorporate the evaluation of study notes into the "learning portfolio", and fully mobilize the subjective initiative of students. 4. "Project-based Learning" post-class improvement assessment. Project-driven constructive course papers require students to organize their own language to answer questions related to the course, based on a specific teaching goal, to evaluate students' knowledge and skills, development abilities, etc. through teaching, and not to compare with other students' mastery. Through the course paper writing, students have not only exercised the ability to combine language knowledge with practice, but also laid a certain foundation for the writing of graduation thesis. Therefore, it can be said that the course paper writing process is the training process of comprehensive ability.

4) Evaluation Subject Reform

\begin{tabular}{|c|c|c|c|c|c|c|c|c|}
\hline \multicolumn{8}{|c|}{ (Course Study Portfolio) Formative Evaluation $70 \%$} & \multirow{2}{*}{$\begin{array}{l}\text { Summative } \\
\text { Evaluation } \\
30 \%\end{array}$} \\
\hline \multicolumn{3}{|c|}{$\begin{array}{l}\text { Online self-learning before } \\
\text { class } 20 \%\end{array}$} & \multicolumn{3}{|c|}{$\begin{array}{l}\text { Classroom partner-based interactive } \\
\text { learning } 30 \%\end{array}$} & \multicolumn{2}{|c|}{$\begin{array}{l}\text { Feedback after class } \\
20 \%\end{array}$} & \\
\hline $\begin{array}{l}\text { Lecture } \\
\text { video }\end{array}$ & $\begin{array}{l}\text { Online } \\
\text { learning } \\
\text { \&commu } \\
\text { nication }\end{array}$ & $\begin{array}{l}\text { Online } \\
\text { test }\end{array}$ & $\begin{array}{l}\text { Personal } \\
\text { learning } \\
\text { log }\end{array}$ & $\begin{array}{c}\text { Group } \\
\text { display } \\
\text { mutual } \\
\text { evaluation }\end{array}$ & $\begin{array}{l}\text { Teacher- } \\
\text { student } \\
\text { interaction } \\
\text { in the group }\end{array}$ & $\begin{array}{l}\text { After- } \\
\text { school } \\
\text { notes }\end{array}$ & $\begin{array}{l}\text { Course } \\
\text { Paper }\end{array}$ & Final exam \\
\hline $5 \%$ & $5 \%$ & $10 \%$ & $10 \%$ & $10 \%$ & $10 \%$ & $5 \%$ & $15 \%$ & $30 \%$ \\
\hline
\end{tabular}

5) Full Management of the Growth Portfolio to Ensure Sustainable Development

The project reform uses three effective ways to establish the "evaluation portfolio" of students' academic performance: The first is based on students' flipping and independent online learning, discussion, and self-test before class, it records students' learning initiative and depth of thinking, which is helpful for teachers to grasp the students' cognitive starting point, cognitive characteristics and cognitive level; The second is based on the performance of students' interactive learning in the classroom. The teacher records the "demonstration" of the effect of self-study conducted in small groups, the questioning and inquiry between students, the answering and discussion between teachers and students; the third is based on the feedback and innovative learning of students after class, teachers evaluate students' after-school study notes, and evaluate course papers written by students on related issues.

\section{The Experimental Process}

\subsection{Preparation Phase}

To study the newly released "National Standards for the Teaching Quality of Foreign Languages and Literatures" and "China Standards of English", and related theories of testing, to consult relevant experts, and to formulate the evaluation content and evaluation criteria of the "Advanced English" dynamic evaluation mode. At the same time, to combine Chinese and foreign literature to obtain the setting situation of the course, to establish a test question bank for the quantitative evaluation of the course. To help students learn the knowledge of each chapter in advance, to combine the key points and difficulties of each chapter's teaching, and the students' cognitive laws to carefully compile and design the instructive and guiding "flipped classroom self-learning task list". 


\subsection{Execution Phase}

To establish learning corpus and lesson plan database for pre-class learning. The course learning corpus contains multiple texts (involving news, background, academic papers, etc. related to the chapters studied) to help students obtain the background and extended information of the learning content for student perceptual analysis. The lesson plan database is based on the key points of each chapter's teaching, language difficulties, and students' cognitive laws, carefully compiling and designing instructive and guiding "flipped classroom self-learning tasks" and guiding questions. Perceptual analysis of corpus and online learning, discussion, and self-test are the first basis for "portfolio evaluation method".

To establish a learning community, according to the grouping principle of "heterogeneity within a group and homogeneity between groups", the students in a class (about 24 students) are divided into 5 groups, and the group leader takes turns in charge. In classroom learning, the teacher collects the submitted cooperative learning records before the end of the class, and makes detailed records based on each student's current classroom performance, and makes corresponding evaluations based on the logic, innovation, and speculative nature of the students' speech in classroom learning. In the process of cooperative learning, students themselves and students have a deeper understanding of themselves and the performance of others. Teachers encourage students to conduct self-evaluation and mutual evaluation of their performance. Teachers guide students to use a series of methods to record the progress, achievements, and shortcomings of themselves and their classmates, and evaluate them according to the standards jointly established by teachers and students. This method of evaluation has changed the past evaluation by the teacher alone, and students are in a passive evaluation form of being evaluated. In addition, teachers can get feedback information for improving education and teaching from the evaluation, and use this as the second basis for the "portfolio evaluation method".

To develop a guidebook for mutual evaluation ability, regularly check students' study notes, and establish a student mutual evaluation form based on the content of each chapter and each task. The form reflects the evaluation dimensions of key knowledge, the ability of representation and responding to questions, etc., and is compiled into a booklet. The "Advanced English" textbook contains more chapters and more difficult knowledge points. It is more difficult for students to master and absorb. Nowadays, multimedia teaching methods are used in the classroom. The teaching pace of the classroom is fast and the teaching content is large. It is difficult for students to digest and absorb the knowledge taught by the teacher on the spot in the classroom. They must review, absorb and consolidate well outside the class. This can not only increase their interest, but also increase their depth of learning, and truly cultivate their independent thinking ability. And its evaluation can be taken as the third basis of the "portfolio evaluation method".

To establish project-oriented tasks, regularly collect each student's course papers, course papers are generally in the form of topical research, such as "How to understand the writing technique of narration", "How to evaluate the character of Ogilvie", " The difference between the two rhetorical devices of transferred epithet and personification", which not only assess the content of classroom teaching but also expand the content of teaching, and are not difficult for students simultaneously. And we take its evaluation as the fourth basis of "Portfolio Evaluation Method".

After nearly 4 months of practice, the corresponding evaluation basic database was established based on the two class samples, the students' "learning portfolio" and related experimental data and materials were sorted out, and the corresponding result data presented in the "course learning portfolio" were analyzed. Simultaneously this evaluation system attempts to use the completion status of each student's self-learning task list and course papers as a data base to make diagnostic evaluations of students' common problems, and as the focus of future teaching.

\section{Results and Discussion}

Adopting dynamic evaluation in the learning process of the "Advanced English" course can mobilize students' learning initiative, it is a constructive evaluation mechanism reform and it is also a teaching evaluation reform to improve the ecology of teaching and learning. First of all, the dynamic evaluation based on the classroom activities of "flipped classroom" and "peer instruction" is clearly-targeted and constructive. This classroom activity puts the teaching subject and the teaching object in the right position, and establishes a positive stimulating interactive relationship between teaching and learning. Although compared with other courses, the language content of Advanced English is more difficult and the subject matter is more diverse, and students have a greater difficulty in understanding and appreciating it, but it is still feasible to analyze and conduct classroom discussions in classroom teaching. Students of the upper grades have a certain ability of language expression. Discussions in the classroom not only exercise students' ability to use language, but also deepen students' understanding of knowledge and theories. This kind of dynamic evaluation can provide teachers and students with feedback information on learning status, thereby regulating and enhancing teaching and learning activities.

Secondly, the dynamic evaluation of post-class promotion learning activities "Note-taking" and "Project-based Learning" is an important teaching strategy to establish a good feedback and incentive mechanism. This is a key measure to establish a dynamic closed loop of teaching, i.e. "learning-digesting-consolidating-upgrading". The purpose of senior students to learn professional courses well is to consolidate basic knowledge, be good at analyzing problems, and use what they have learned to solve practical problems. Study notes are based on the extracurricular digestion and absorption of class notes, resummarizing the knowledge learned, adding their own knowledge components, and deepening the knowledge learned more comprehensively and systematically. This can not only increase their interest, but also increase their depth of learning, and truly cultivate their independent thinking ability. 
Research paper writing is an important way to train students to think about, analyze and solve problems. Learning to write research papers is a good and productive practice by students to develop academic activities, to pave the way for future graduation thesis writing, and to be necessary to exercise students' practical ability. Course paper writing is not only the deepening and extension of textbook content, but also the improvement and strengthening of students' thinking training and inquiry ability, which is not only necessary, but also feasible. The writing of course papers can provide teachers with a view of students' activities inside and outside of the classroom and the learning results, and through discussions and interviews, the learning process of learners can be observed, evaluated and monitored. The process of guidance and evaluation in this way is a dynamic evaluation process.

Thirdly, the transformation of the roles of teachers and students has brought great endogenous vitality to this reform of teaching practice. Both teachers and students are fully aware of their own status and role in the new evaluation system, especially the teacher's initiative to adapt to the transition of roles, that is, from the original knowledge transmitter to multiple roles, integrating knowledge interpreters, activity organizers, activity participants and behavior monitors into one; students are the main body of learning and evaluation, teachers involve students in the process of learning and evaluation, guiding students to learn to evaluate, effectively self-monitoring their own learning process, and improving learning effects.

The teaching practice of this dynamic evaluation mode can bring several important enlightenments to the reform of the similar sort of teaching evaluation mechanism:

1) Establishing the standard

After the construction of the dynamic teaching evaluation mode, the biggest problem faced in the implementation process is the determination of the evaluation standard, that is, the evaluation reliability problem. Different teachers may have very different evaluation standards for students, and the standards used by students in self-evaluation and mutual evaluation may also be inconsistent. Even the same teacher may have different judgment standards due to some non-evaluative factors at different times. Therefore, in the implementation process, we must focus on grasping the scientificity, consistency, comprehensiveness and feasibility of the evaluation standards. And for the characteristics of the teaching contents, it is necessary to formulate different appropriate evaluation standards according to the nature of different disciplines and different courses. Such evaluation standards include not only evaluation standards for students' basic knowledge and basic skills, but also evaluation standards for students' practical application ability, thinking ability, critical ability and innovation ability.

2) Determining the result

When students evaluate each other, they are supposed to dilute grades and scores. From the perspective of promoting student growth, we guide students to pay attention to the description of their classmates' true performance, pay attention to the highlights and strengths of classmates, and emphasize self-expression and reflection, so that students can learn from others. Students should not be allowed to focus on scoring or grading each other. If being burdened by grades and grades, students will not be convinced of each other. They only pay attention to each other's weakness and shortcomings, to oneself they only see the merits. Therefore, evaluations should avoid being turned into faults-picking and accusing each other.

3) Complementary evaluation methods

The assessment of students' mastery of basic language knowledge is based on the teaching syllabus and examination syllabus to examine students' knowledge structure and the evaluation of the overall grasping ability of the system, which adopts a quantitative evaluation method. A comprehensive evaluation method (combination of in-class and extra-curricular) is adopted to evaluate students' ability to use language knowledge. At the same time, formative evaluation and summative evaluation are combined to give full play to the advantages of both, to evaluate students reasonably, and to achieve diversity, fairness and comprehensiveness in teaching evaluation to promote the overall development of students' abilities

This evaluation mode reform is an experiment in teaching to touch the change of the entire teaching ecology. It will stimulate the best matching mode of teaching and learning and good teaching effects. The most important purpose of evaluation is not to prove, but to improve. By creating a dynamic "learning evaluation portfolio" for students, it is possible to shift the focus from testing to focus on the learning process, and to maximize the role of evaluation in teaching; through the transition from summative evaluation-oriented to formative evaluation, the focus on learning process and learning results are effectively combined, and the teaching method is transformed from teaching-oriented to learning-oriented.

Through the empirical study of the evaluation mode in Advance English teaching, we try to explore the mode shift from classroom teaching to a combination of inside and outside classes to promote the improvement of teaching quality and achieve the teaching goals of the course, focus on the combination of students' theory and practice and on the improvement of practical application ability while mastering basic knowledge, and inspire and train students interest in learning, build a sense of achievement and self-confidence in learning, and improve the ability to comprehensively use language.

\section{Acknowledgement}

This paper is supported by Zhejiang University of Finance \& Economics Dongfang College teaching reform research key project in the year 2019 "Research on the Formative Evaluation Model of "Advanced English" (2019JK36). 


\section{References}

Ableeva, R. (2010). Dynamic Assessment of Listening Comprehension in Second Language Learning. PhD dissertation, the Pennsylvania State University.

Budoff, M.. (1999). The Validity of Learning Potential Assessment. In C.S.Lidz (Ed), Dynamic Assessment: An Interactional Approach to Evaluation Learning Potential. NewYork: Guilford Press.

Burns, M.S., N. J. Vye \&. J. D. (1998). Bransford. Static and Dynamic Measures of Learning in Young Handicapped Children. Diagnostique, (2), 59-63.

Campione, J. C. \& Brown, A. L. (1999). Linking Dynamic Assessment with School Achievement. In C.S.Lidz (Ed), Dynamic Assessment: An Interactional Approach to Evaluation Learning Potential. NewYork: Guilford Press.

Chen Dandan. (2021). The Impact of Online Peer Feedback on English Writing Performance from the Perspective of Dynamic Assessment. Technology Enhanced Foreign Languages, 198(2), 17-24.

Feuerstein, R. (1990). The Dynamic Assessment of Related Performers: The Learning Potential Assessment Device, Theory, Instrument, and Techniques. Baltimore, MD: University Park Press.

Lantolf, J. P. \& M. E. Poehner. (2004). Dynamic assessment: Bringing the past into the future. Journal of Applied Linguistics, (1), 49-74.

Li Dandi. (2015). Research on English Linguistics Curriculum Evaluation Mode Based on Dynamic Evaluation Theory. Foreign Language World, (6), 19-25.

Li Fengqing \& Han Xiaoling. (2017). The Construction and Demonstration of a Blended Teaching Quality Evaluation System. China Audio-visual Education, 370( 11), 108-113.

Li Kunchong. (2001). Diversified Teaching Evaluation, Taiwan: Psychological Press, (6), 309-313.

Naeini, J. (2014). On the study of DA and SLA: Feuerstein's MLE and EFL learners' reading comprehension. Procedia-Social and Behavioral Sciences, 98, 1297-1306.

Petersen, D. B., M. M. Allen \& T. D. Spencer. (2016). Predicting reading difficulty in first grade using dynamic assessment of decoding in early kindergarten: A large -scale longitudinal study. Journal of Learning Disabilities, 49(2): 200-215.

Vygotsky, L.S. (1987). Mind in Society: The development of Higher Psychological Processes, Cambridge: Harvard University Press. 